\title{
STRATEGI HAKIM MEDIATOR DALAM MENCEGAH TERJADINYA PERCERAIAN
}

\author{
Khoirul Anam \\ Hukum/Universitas Tulungagung \\ anamicku@yahoo.com
}

\begin{abstract}
ABSTRAK
Strategi Hakim Mediator Dalam Mencegah Terjadinya Perceraian, Studi di Pengadilan Agama Tulungagung adalah Judul dari penelitian ini, hal ini menarik di angkat sebagai judul, disebabkan tingginya perceraian setiap tahunya pada wilayah Kabupaten Tulungagung, dapat kita lihat pada tahun 2008 - 2012 dan terakhir bulan Juni 2013 jumlah pemohon meningkat. Hal ini memunculkan dua pertanyaan. Pertanyaan, pertama adalah Faktor apa penyebab timbulnya perceraian di Pengadilan Agama Tulungagung? dan yang Kedua adalah, bagaimana Strategi Hakim Mediator dalam mencegah terjadinya perceraian di Pengadilan Agama Tulungagung?. Tujuan dari Penelitian ini adalah untuk menganalisis faktor penyebab perceraian pada Pengadilan Agama Tulungagung serta untuk menganalisa Strategi Hakim Mediator melakukan pendekatan kepada para pihak agar tidak terjadi perceraian.

Untuk mendapatkan pemahaman yang utuh tentang Strategi Hakim Mediator Dalam Mencegah Terjadinya Perceraian Di Pengadilan Agama Tulungagung ini, di perlukan metode yang mampu untuk menjawab rumusan masalah atau pertanyaan diatas, maka peneliti menggunakan metode kualitatif. Dengan Pendekatan penelitian tersebut bertujuan memperoleh data lebih lengkap, sesuai konsep Pendekatan penelitian kualitatif. Sedangakan untuk teknik pengumpulan datanya dengan menggunkan teknik observasi, wawancara mendalam, serta dokumentasi.

Dari hasil penelitian tentang Strategi Hakim Mediator Dalam Mencegah Terjadinya Perceraian, Studi Di Pengadilan Agama Tulungagung ini adalah, ada beberapa faktor yang menyebabkan orang mengajukan permohonan cerai di antaranya, faktor tidak adanya tanggung jawab suami terhadap keluarga, adanya Kekerasan dalam keluarga, tidak adanya keharmonisan di dalam keluarga, adanya faktor ekonomi atau kurangnya nafkah kepada istri, Serta adanya gangguan dari luar (Perempuan atau laki laki lain). Sedangkan untuk strategi Hakim Mediator dalam melaksanakan mediasi untuk mencegah terjadinya perceraian dengan menggunakan beberapa strategi atau pendekatan, di antaranya adalah pendekatan agama, pendekatan masa lalu atau mengingat masa-masa romantis, Pendekatan Matematis, dan Pendekatan Keluarga (anak atau orang tua) serta Pendekatan Psikologis kepada para pihak.
\end{abstract}


Dari kesimpulan dan temuan diatas, ada beberapa saran khususnya kepada Pengadilan Agama Tulungagung dan Mahkamah Agung yaitu, a) Pengadilan Agama Tulungagung perlu mendorong kepada Hakim Mediator untuk mengikuti pendidikan dan pelatihan khusus Mediasi. b) Mahkamah Agung perlu membuat buku saku khusus tentang petunjuk praktis pendekatan Mediasi untuk pegangan Hakim mediator atau mediator.

Kata Kunci: Hakim, Perceraian, Mencegah, Mediator.

\title{
MEDIATOR JUDGE'S STRATEGY IN PREVENTING DIVORCE
}

\begin{abstract}
The Mediator Judge's Strategy in Preventing Divorce, Studies at the Tulungagung Religious Court is the title of this study, it is interesting to be appointed as a title, due to the high divorce rate every year in the Tulungagung Regency area, we can see in 2008 2012 and last June 2013 the number of applicants increases. This raises two questions. The first question is what are the factors that cause divorce in the Tulungagung Religious Court? and the second is, what is the strategy of the Mediator Judge in preventing divorce in the Tulungagung Religious Court?. The purpose of this study is to analyze the factors that cause divorce at the Tulungagung Religious Court and to analyze the Mediator Judge's Strategy to approach the parties so that divorce does not occur.

To get a complete understanding of the Mediator Judge's Strategy in Preventing Divorce in the Tulungagung Religious Court, a method is needed that is able to answer the problem formulation or question above, the researchers used qualitative methods. With this research approach, it aims to obtain more complete data, according to the concept of a qualitative research approach. As for the data collection techniques using observation techniques, in-depth interviews, and documentation.

From the results of research on the Mediator Judge's Strategy in Preventing Divorce, the Study at the Tulungagung Religious Court is, there are several factors that cause people to apply for divorce including, the factor of the husband's lack of responsibility towards the family, the existence of violence in the family, the absence of harmony in the family. in the family, the existence of economic factors or lack of living for the wife, as well as interference from outside (women or other men). As for the Mediator Judge's strategy in carrying out mediation to prevent divorce by using several strategies or approaches, including the religious approach, the past approach or remembering romantic times, the Mathematical Approach, and the Family Approach (child or parent) as well as the Psychological Approach. to the parties.

From the conclusions and findings above, there are several suggestions, especially to the Tulungagung Religious Court and the Supreme Court, namely, a) The Tulungagung Religious Court needs to encourage Mediator Judges to take special education and training in Mediation. b) The Supreme Court needs to make a special pocket book on practical guidelines for the Mediation approach for the guidance of the mediator Judge or mediator.
\end{abstract}

Keywords: Judge, Divorce, Prevent, Mediator. 


\section{A. PENDAHULUAN}

Mediasi adalah proses negosiasi pemecahan masalah di mana diperlukan Penengah dalam menyelesaiakan persengketaan para pihak.

Dalam kamus besar bahasa Indonesia, kata mediasi diberi arti sebagai proses pengikut sertaan pihak ketiga dalam penyelesaian suatu perselisihan sebagai penasihat.

Dalam konsep Peradilan, Mediasi menjadi bagian terpenting dalam proses tahapan perceraian di Pengadilan Agama. Hal ini dapat dilihat dalam regulasi yang mengatur Pernikahan atau perceraian. Dari beberapa pengertian di atas dapat dipahami bahwa dalam penyelesaian sengketa harus berasas pada musyawarah mufakat, asas ini merupakan nilai tertinggi yang dijabarkan lebih lanjut dalam Undang-Undang Dasar 1945 dan sejumlah peraturan perundang-undangan di bawahnya, di antara yang disebutkan dalam yang disebutkan dalam penjelasan Pasal 3 ayat 2 UndangUndang No 14 Tahun 1970 yang telah dirubah dengan Undang-Undang No 4 Tahun 2004 yang telah dirubah dengan Undang-Undang No 48 Tahun 2009 Tentang Kekuasaan Kehakiman yakni “ Peradilan negara menerapkan dan menegakan hukum dan keadilan berdasarkan Pancasila".

Peraturan di atas sama dengan semangat dalam Islam yang senantiasa mengusung perdamaian khususnya dalam konsep perkawinan, dalam Islam perkawinan adalah ikatan lahir batin antara seorang laki-laki dengan seorang perempuan sebagai suami istri dengan tujuan membentuk keluarga yang sakinah, mawaddah, wa rah\}mah. Sedangkan perceraian atau talak adalah hal yang sangat di benci oleh Allah SWT.

Dalam konteks Peradilan Agama Munculnya permohonan perceraian tidak lepas dari beberapa faktor penting dalam permasalahan yang ada di masyarakat dan keluarga mulai dari permasalahan di ranjang sampai permasalahan ekonomi. Hal ini juga terjadi di Pengadilan Agama Tulungagung, beberapa masalah yang membuat keretakan keluarga tetap menjadi penyebab orang untuk mengajukan permohonan perceraian di Pengadilan Agama Tulungagung. Hal ini bersumber dari catatan kasus perceraian di Pengadilan Agama Tulungagung penyebab perceraian lainnya adalah karena suami yang kurang bertanggung jawab, dan gangguan pihak 
ketiga. Selain itu, menurut Sekretaris Pengadilan Agama Kabupaten Tulungagung, banyaknya masyarakat yang bekerja di luar negeri, atau menjadi TKI, juga banyak menjadi penyebab perceraian, Persoalan inilah yang menjadikan kasus perceraian di Kabupaten Tulungagung terus meningkat. Kalau di tahun 2011 terjadi 1729 kasus, maka di tahun 2012, naik menjadi 1870. Di tahun ini, sampai bulan Januari 2013 kemarini, tercatat di Pengadilan Agama Tulungagung sudah menangani 175 kasus perceraian.

Dalam kondisi ini maka menjadi satu tantangan tersendiri yang harus di lakukan oleh Pengadilan Agama Tulungagung untuk mengadakan beberapa tahapan prosedur yang diamanahkan peraturan yang ada, guna mencegah terjadinya putusan perceraian di Pengadilan Agama Tulungagung.

Hal di atas tidak lepas dari peran dan strategi Hakim Mediator yang di tunjuk oleh Ketua Pengadilan Agama untuk menjadi mediator dalam proses perdamaian antara kedua belah pihak. Strategi menurut Kamus Ilmiah adalah ilmu siasat perang atau muslihat untuk mencapai sesuatu. Strategi yang benar dan baik akan mempermudah hakim mediator dalam memberikan solusi yang terbaik kepada kedua belah pihak untuk mendapatkan kepuasan yang sama, yang akhirnya tidak terjadi putusan perceraian.

Dalam konteks pemahaman strategi di atas seorang Hakim mediator harus mempunyai cara atau strategi guna untuk mencegah dan meminimalisir terjadinya perceraian. Mencegah di sini seorang hakim mampu mendamaikan kedua belah pihak tanpa ada yang di rugikan. Kalau kita melihat dari beberapa tulisan yang ada pengertian cegah mempunyai arti menahan agar sesuatu tidak terjadi. Suatu yang terjadi di sini adalah terjadinya perceraian.

Berkaitan dengan peran dan fungsi mediator yang sangat penting dalam proses mediasi di Pengadilan Agama, Mahkamah Agung diharapkan dapat segera mengadakan pelatihan-pelatihan untuk para hakim di Pengadilan Agama di daerah-daerah, sehingga para hakim yang menjadi mediator mendapat wawasan yang cukup untuk melaksanakan mediasi. Para Hakim mediator, diharapkan untuk mempelajari lebih dalam mengenai 
mediasi baik dari jurnal-jurnal maupun melalui internet atau tulisan-tulisan yang ada, sehingga mendapatkan wawasan yang luas terkait mediasi. Mengingat waktu yang diberikan untuk mediasi dengan mediator dari dalam Pengadilan Agama cukup sedikit, maka diharapkan para hakim mediator dapat menyusun strategi-strategi yang tepat sehingga lebih bisa memanfaatkan waktu dengan baik, hal inilah yang harus dilakukan oleh Hakim Mediator di Pengadilan Agama Tulungagung agar mampu mencegah terjadinya putusan perceraian di sisi yang lain dan di sisi lainnya mampu untuk melaksanakan amanah undang-undang dan peraturan yang ada demi tegaknya hukum dan keharmonisan dalam membangun keluarga yang sakinah, mawadah warahmah.

Berangkat dari sinilah diperlukan penelitian tentang strategi Hakim Mediator dalam mencegah terjadinya perceraian di Pengadilan Agama Tulungagung, hal ini sangat penting guna menciptakan keluarga yang harmonis dan sejahtera di Kabupaten Tulungagung.

\section{B. Rumusan Masalah}

Berdasarkan penjelasan di atas, maka peneliti membuat rumusan masalah sebagai berikut:

a. Faktor apa yang menyebabkan timbulnya permohonan perceraian di Pengadilan Agama Tulungagung?

b. Bagaimana strategi Hakim Mediator di Pengadilan Agama Tulungagung dalam mencegah terjadinya perceraian.

\section{Tujuan Penelitian}

Sesuai dengan rumusan masalah di atas, maka penelitian ini bertujuan:

1. Untuk menganalisis faktor yang menyebabkan timbulnya permohonan perceraian di Pengadilan Agama Tulungagung.

2. Untuk menganalisis Strategi Hakim Mediator di Pengadilan Agama Tulungagung untuk mencegah terjadinya perceraian. 


\section{Metode Penelitian}

Untuk mendapatkan pemahaman yang utuh tentang Strategi Hakim Mediator dalam mencegah terjadinya perceraian di Pengadilan Agama Tulungagung, di perlukan satu metode yang mampu menjawab rumusan penelitian masalah di atas, maka di sini peneliti menggunakan metode penelitian kualitatif.

Demikian halnya dengan penelitian ini untuk memahami dan menganalisis maksud para pihak yang bersengketa dan para Hakim untuk melakukan pendekatan perdamaian agar para pihak mampu di damaikan dan tidak terjadi putusan cerai.

Berangkat dari hal ini, maka data-data penelitian yang diperlukan dalam penelitian ini adalah sebagai berikut

1. Data yang akan dikumpulkan adalah:

a. Data yang berkaitan dengan Hakim Agama di Pengadilan Agama Tulungagung

b. Surat penunjukan Hakim Agama Pengadilan Agama Tulungagung sebagai Hakim Mediator

c. Data yang berkaitan tentang data pemohon yang masuk dan data yang di putus maupun data yang di cabut, yang disebabkan hasil proses mediasi

2. Cara Mendaptakan Data

Penelitian ini bersumber dari data yang di peroleh dan data yang di gunakan dalam penelitian ini adalah bersumber pada wawancara dan Observasi/Pengamatan dalam proses mediasi yang dilakukan Hakim Mediator di Pengadilan Agama Tulungagung.

Sumber data pokok yang di peroleh adalah dari:

a. Data tentang Hakim Agama Tulungagung

b. Alasan Hakim Ketua Pengadilan Agama Tulungagung dalam penunjukan Hakim Agama sebagai Hakim Mediator

c. Panitera Sekretaris

d. Data tentang jumlah perceraian yang diputus dan dicabut di Pengadilan Agama Tulungagung

3. Cara Pengumpulan Data 
Idealnya dalam sebuah penelitian kualitatif terdapat beberapa teknik pengumpulan data yang lazim di gunakan, yaitu observasi berperan serta (participant observation), wawancara mendalam (in dept interview) dan dokumentasi.

\section{E. Hasil Penelitian}

1. Faktor Penyebab Terjadinya Permohonan Cerai Di Pengadilan Agama Tulungagung

Beberapa faktor penyebab perceraian yang paling banyak berdasarkan data mulai tahun 2008 sampai dengan 2012 dan berdasarkan wawancara dengan Hakim Mediator adalah Tidak ada tanggung jawab suami khususnya, di susul tidak adanya keharmonisan di dalam keluarga lalu dilanjutkan dengan masalah ekonomi, serta munculnya pihak-pihak ketiga dalam rumah tangga atau Pria idaman lain/wanita idaman lain.

2. Analisis Strategi Hakim Mediator Pengadilan Agama Tulungagung Dalam Mencegah Terjadinya Perceraian.

Dalam melaksanakan mediasi di Pengadilan Agama Tulungagung ini, Hakim Mediator menggunakan dasar hukum yang ada yaitu Peratura Mahkmah Agung, serta untuk wilayah Pengadilan Tinggi Agama Surabaya diterbitkannya surat nomor W13A/3804/0T.01.3/X/2012, Perihal tentang Mediasi, hal ini dijelaskan dalam isi surat berdasarkan hasil temuan dalam proses perkara banding dan hasil observasi di beberapa Pengadilan Agama, ternyata masih banyak pelaksanaan proses mediasi baik dalam tahapan tahapannya maupun teknisnya masih jauh dari tujuan Peraturan Mahkamah Agung nomor 1 Tahun 2008, sehingga terkesan asal-asalan. Maka di terbitkanlah tahapan tahapan pelaksanaan mediasi di wilayah Pengadilan Tinggi Agama Surabaya.

Dalam melaksanakan proses mediasi ini, para Hakim mediator harus mampu mempunyai kemampuan untuk mengomunikasikan kepada para pihak agar terjadi sebuah perdamaian. Ikhtiar untuk mencapai proses perdamaian ini para Hakim Mediator harus 
menggunakan tahapan-tahapan mediasi di Pengadilan Agama, yang di keluarkan oleh Pengadilan tinggi Agama Surabaya nomor W 13A/3185/HK.05/X/2011, Dalam Tahapan yang pertama mediasi, Hakim Mediator harus melakukan pembukaan dulu, pembukaan di sini adalah dengan ucapan sukur kepada Allah SWT yang mudah-mudahan Mediasi ini sukses tanpa ada halangan apa-apa. Setelah itu dilanjutkan dalam perkenalan mediasi, dalam perkenalan ini Mediator menerangkan pengertian dan pentingnya Mediasi. Serta setelah itu perkenalan para pihak. Dalam perkenalan para pihak. Setelah perkenalan mediator mencoba untuk mengajak para pihak menyepakati pertemuan mediasi ini dilanjutkan atau diagendakan kapan, sesuai keinginan para pihak.

Setelah proses pembukaan, perkenalan Mediasi, serta perkenalan para pihak di lanjutkan Hakim Mediator mulai menanyakan akar masalahnya kenapa terjadi permohonan cerai talak atau cerai gugat. Setelah para pihak menceritakan alasan alasannya.

Setelah Hakim mediator mengetahui masalanya mulailah Hakim Mediator menggunakan pendekatan atau dengan mulai memberi nasihat-nasihat, ada yang menggunakan nasihat dengan menggunakan pendekatan Agama. Dalam pendekatan agama ini mediator menggunakan beberapa dalil yang membicarakan dan membahas tentang agama.

Selain pendekatan Agama di atas Hakim Mediator menggunakan pendekatan matematis. Pengertian pendekatan matematis ini adalah biaya hidup pasca perceraian itu sangat tinggi, ketika para pihak sudah pisah mereka akan segera menikah lagi, apakah mau suami atau istri baru saudara diajak mengasuh anak saudara. Belum lagi harus menghidupi dua keluarga. Selain pendekatan matematis pendekatan keluarga, Pendekatan ini penekanya adalah bagi para pihak yang mempunyai anak, karena anak adalah dianggap sebagai simbol pemersatu atau pengikat sebuah keluarga, Selain pendekatan di atas adalah dengan pendekatan secara Psikologis, pendekatan ini adalah menggunakan pendekatan hati ke hati antar para pihak, bagaimana seorang Mediator mencoba menyentuh hati para pihak. 
Dengan pendekatan psikologis ini di yakini bisa menyadarkan para pihak untuk berdamai. Yang terakhir adalah strategi Hakim Mediator dengan menggunakan pendekatan masa lalu, terkait pendekatan ini penekanan pada pasangan yang dulu mempunyai masamasa pacaran atau pada masa awal pernikahan. Karena pada awal pernikahan ini menurut hakim mediator di yakni bisa meredam sebuah gejolak dalam bahtera rumah tangga, karena rumah tangga yang baik adalah rumah tangga yang selalu mengingat kebaikan dan melupakan masa lalu yang salah atau kurang baik.

Dari beberapa pendekatan hakim mediator yang ada di Pengadilan Agama Tulungagung yang telak diterangkan dalam bab sebelumnya dapat kita ringkas sebagai berikut:

\begin{tabular}{|l|l|l|}
\hline No. & \multicolumn{1}{|c|}{$\begin{array}{c}\text { Hakim } \\
\text { Mediator }\end{array}$} & \multicolumn{1}{c|}{$\begin{array}{c}\text { Pendekatan Mediasi Untuk Mencegah } \\
\text { Terjadinya Perceraian }\end{array}$} \\
\hline 1. & Roji,un & $\begin{array}{l}\text { Pendekatan Agama, Pendekatan masa lalu saat } \\
\text { pacaran }\end{array}$ \\
\hline 2. & Toif & $\begin{array}{l}\text { Pendekatan matematis, Pendekatan akar masalah } \\
\text { keluarga }\end{array}$ \\
\hline 3. & Siti Roikanah & Pendekatan Agama, Pendekatan Keluarga \\
\hline 4. & Khutobiin & Pendekatan Psikologis, Pendekatan anak \\
\hline 5. & Muh Affandi & Pendekatan masa lalu, Pendekatan anak \\
\hline 6. & Romelan & Pendekatan agama \\
\hline 7. & Mubahi & Pendekata keluarga \\
\hline 8. & Hayat & Pendekatan agama \\
\hline 9. & Zaenal Arifin & Pendekata Keluarga, Pendekatan Psikologi \\
\hline
\end{tabular}

Kalau kita melihat dari pendekatan Hakim mediator di Pengadilan Agama Tulungagung tentang melakukan proses mediasi antar para pihak di ruang mediasi adalah bagian dari kemampuan atau kelebihan individu para Hakim Mediator dalam mencegah terjadinya perceraian, karena di dalam peraturan yang ada, yaitu Peraturan Mahkamah Agung Nomor 1 Tahun 2008 Tentang Prosedur Mediasi di Pengadilan Agama Mahkamah Agung Republik Indonesia. Serta Surat Dari Pengadilan Tinggi Agama Surabaya bernomor: W13-A/3185/HK.05/X/2011 tentang tahapan-tahapan Pelaksanaan 
mediasi, tidak mencantumkan secara tertulis tentang pendekatan para Hakim Mediator dalam mencegah terjadinya perceraian.

Strategi atau pendekatan Hakim Mediator yang di jelaskan di atas belum bisa memberikan secara penuh atau maksimal dalam pencegahan perceraian di Pengadilan Agama Tulungagung. Hal ini dapat kita lihat dari meningkatnya permohonan perceraian di Pengadilan Agama Tulungagug setiap tahunya.

\section{F. Kesimpulan}

Dari hasil penelitian diatas maka dapat disimpulkan sebagai berikut:

1. Faktor penyebab permohonan cerai di Pengadilan Agama Tulungagung adalah disebabkan beberapa faktor, di antaranya adalah “
a. Faktor tidak adanya tanggung jawabnya suami terhadap keluarga
b. Adanya Kekerasan dalam keluarga
c. Tidak adanya keharmonisan di dalam keluarga
d. Adanya faktor ekonomi atau kurangnya nafkah kepada istri
e. Serta adanya gangguan pihak ketiga (mempunyai pria idaman lain atau wanita idaman lain).

2. Strategi Hakim Mediator dalam mencegah terjadinya perceraian di Pengadilan Agama Tulungagung adalah dengan menggunakan beberapa pendekatan, di antaranya adalah
a. Dengan menggunakan pendekatan agama
b. Pendekatan masa lalu atau mengingat masa-masa romantis
c. Pendekatan Matematis
d. Pendekatan Keluarga (anak atau orang tua)
e. Pendekatan Psikologis.

\section{G. Saran-Saran}

1. Bahwa kedepan diperlukan Buku Saku yang baik untuk pegangan Mediator dalam menyelesaiakan perdamaian atau mediasi untuk mencegah perceraian.

2. Bahwa diperlukan Mediataor yang berasal dari luar Hakim Pengadilan Agama. 


\section{DAFTAR PUSTAKA}

Abbas,Syahrizal, Mediasi dalam Perspektif HukumSyari'ah, Hukum Adat, dan HukumNasional, Kencana Prenada Media Group, Jakarta, 2009.

AhamadHasanMunawir, AlMunawir Kamus Arab Indonesia, Yogyakarta, Ponpes Al Munawir Krapyak 1984.

A,Pius, Partanto, Kamus Ilmiah Populer, Surabaya: Arkola Surabaya, 2001.

Abdul, Manan, Penerapan HukumAcaraPerdata di Lingkungan Peradilan Agama, Jakarta: Prenada Media, 2005

Abdurahman, Kompilasi Hukum Islam di Indonesia, Jakarta: CV. Akademika Presindo,1995

AbiAbdillahbinYazid Al Qazwani, Sunan Ibnu Majah, Jilid II, Isa Al Baby Al Halaby, Mesir, 1989

Abu Muhammad Abdullah bin Ahmad bin Muhammad bin Qadama, al-Mugni, Kairo: Hajr li al-Taba'ah wa al-Nashr wa al-Tauzi, 1985

Agustina,Kumala D.S, EfektivitasMediasiPadaPerkaraPerceraian di Pengadilan Agama Lamongan Sebelum dan Sesudah Berlakunya Perma Nomor 1 Tahun 2008 Tentang Prosedur Mediasi. Skripsi pada jurusan Ahwal as-Syakhsiyah Fakultas Syari'ah IAIN SunanAmpel Surabaya, 2010.

Anshary (al), Fathul Wahhab,

Ahmad Ali, Menguak Tabir Hukum,Ghalia Indonesia, Ciawi Bogor, 2008

Mahally (al), Syarah MinhajulThalibin

Al-Mausu'ah al-Islamiyah al-'amah,Kairo: al-Majlis al-A'la li al-Shu'un alIslamiyah, 2001

Departemen. Pendidikandan Kebudayaan, Kamus Besar Bahasa Indonesia, Balai Pustaka, Jakarta,Edisi kedua

Departemen Agama Republik Indonesia, Kompilasi Hukum Acara Islam, Depertemen Agama RI, Jakarta.

EkoSiswanto, "Studi Analisis Tentang Faktor Penyebab Perceraian TKI di Pengadilan Agama Tulungagung" Tesis, Surabaya: IAIN Sunan Ampel Surabaya, 2005

Imam Muhammad bin Isma'il Al Kahlani, Subulussalam, Juz III, Mustafa Al Baby Al Halaby, Mesir, 1973. 
Imam Muhammad bin Ismma'il al-Kahlaany, Sublu al-Salam, Dahlam, Bandung, tth.

Ishadi,“Upaya perdamaian dalam perkara perceraian diPengadilan Agama Tulungagung" Tesis- -Universitas 17 Agustus 1945.

John Echol, KamusInggris Indonesia, cet. Ke XXV, Jakarta; GaramediaPustakaUtama, 2003.

Ruhi al-Ba'labaki, al-Mawarid Arabi-Inglizi, tt, Dar al-Ilmli al- malayin, 1993

S. Nasution, Metode Research (penelitian ilmiah), Jakarta :BumiAksara, 2008 SayyidSabiq, Fiqhus sunnah, Juz III, DaarulBaayan, Kuwait, 1971.

SayidSabiq, Fiqih Sunnah (ter), Jakarta: Pena PundiAksara, 2006

Sugiyono, Memahami Penelitian Kualitatif, Bandung, Alfabeta, Cet. IV, 2008.

SuharsimiArikunto, Prosedur Penelitian Suatu Pendekatan dan Praktek, Jakarta: PT. Rineka Cipta, 2002.

Wahbah al-Zuhayli, al Fiqh al-Islamiwaadillatuh, Damaskus: Dar al-Fikr, 1989.

Undang-Undang Republik Indonesia Nomor 3 Tahun 2006 tentang perubahanatas Undang-UndangNomor 7 Tahun 1989 tentang Peradilan Agama

Undang-Undang No 48 Tahun 2009 TentangKekuasaanKehakiman

Pearturan Mahkamah Agung nomor 1 Tahun 2008 Tentang Prosedur Mediasi di Penagdilan Mahkamah Agung Republik Indonesia

Undang-Undang Republik Indonesia no 41 tahun 2004 Tentang Wakaf

Surat Pengadilan Tinggi Agama Surabaya Nomor: W13A/3185/HK.05/XX/2011. Perihal Tahapan Tahapan Pelaksanaan Mediasi Pengadilan Tinggi Agama Surabaya Nomor: W13-A/3185/HK.05/XX/2011.

Perihal Tahapan Tahapan Pelaksanaan Mediasi

Pengadilan Agama Tulungagung, Matriks Rencana strategi 2010-2014.

Pengadilan Agama Tulungagung, Matriks Rencana strategi 2010-2014.

Pengadilan Agama Tulungagung, Arsip Tahun 2010

Pengadilan Agama Tulungagung, ArsipTahun 2011

Pengadilan Agama Tulungagung, ArsipTahun 2012

Pengadilan Agama Tulungagung, LaporanTahun 2008.

Pengadilan Agama Tulungagung, LaporanTahun 2009. 
Pengadilan Agama Tulungagung, LaporanTahun 2010.

Penagdilan Agama Tulungagung, LaporanTahun 2011.

Penadilan Agama Tulungagung, LaporanTahun 2012

\section{WAWANCARA}

Khutobiin, wawancara, Tulungagung, 26 Juli 2013

MuhAffandi, Wawancara, Tulungagung, 26 Juli 2013

SitiRoikanah, Wawancara, Tulungagung, 26 Juli 2013.

Roji'un, Wawancara, Tulungagung, 21 Juni 2013.

Afwan Puji Prasetiono, Tulungagung, 24 Juli 2013.

Toif, MediasiDalamGugatanRekonpensi, tt

Suyono, Wawancara, 20 Juni 2013

Aam Amrullah, Wawancara, 21 Juni 2013

Mubahi, Wawancara, 29 Juli 2013

Zainal Arifin, Wawancara, 29 Juli 2013

\section{INTERNET}

Liur FM “BuletinTulungagung”, dalam http : // liiurfm . com / site /main .php ?page $=1 \&$ id $=0 \&$ bid $=2081$ (17 April 2013)

http://www.pa.tulungagung.go.id/index.php?option=com_content\&view=ar ticle\&id=48\&Itemid=81 (26 Juli 2013).

http://elhakimi.wordpress.com/2012/11/20/keluarga-dakwahbasiskekuatanumat, (28 Juli 2013)

http://www.artikata.com/arti-323253-cegah.html (8 juni 2013 